\title{
A EXPROMISSÃO E OS SEUS EFEITOS - EFICÁCIA DA NOVAÇÃO E O ARTIGO 838, I DO CÓDIGO CIVIL
}

MENDONÇA, João Josué Walmor de ${ }^{1}$

Recebido em: 2008-01-15

Aprovado em: 2009-04-06

ISSUE DOI: $10.3738 / 1982.2278 .160$

RESUMO: O presente trabalho trata da expromissão, espécie de novação subjetiva passiva. Ocorre quando há substituição do devedor independentemente de sua vontade, por simples ato do credor, substituindo-o por outro devedor. Assim, é a substituição passiva da relação obrigacional na novação quando invocada a espécie da expromissão. Tem efeitos importantes no campo obrigacional, seja no direito creditório, seja no direito locatício. Esse último será o campo de análise da expromissão, a notar seus efeitos, nos deveres e obrigações. A expromissão terá a análise da doutrina e jurisprudência sobre o comportamento e respectiva eficácia. A implicação da expromissão na fiança tem como efeito a sua extinção. Analisar-se-á as variantes componentes da novação por expromissão.

Palavras-chave: Direito Civil. Obrigações. Locação. Fiança. Extinção.

\section{THE EXPROMISSION AND THE EFFECT - NOVATION' EFFICACY AND THE ARTICLE 838, I, OF CIVIL LAW}

SUMMARY: This work deals with the expromission, specie of novation subjective passive. It occurs when there is replacement of the debtor regardless of their will by simple act of the creditor replacing it with debtors. Is the substitution of the debtors in novation when invocation the expromission' specie. It has significant effects on the field obligation, is the credit' right, is the right leasing. The latter is the field of analysis of the expromission, noted their effects, the duties and obligations. The expromission will be analysis of doctrine and jurisprudence about the effect and their efficacy. The expromission implication on bail has the effect of its extinction. Analysis will be the variants in the components of expromission.

Key words: Civil Law. Obligation. Leasing. Bail. Extinction.

\section{INTRODUÇÃOO}

O texto tem a finalidade de analisar a espécie de novação passiva por expromissão. Principalmente do ponto de vista do direito locatício, sem, contudo, deixar de apresentar de forma ampla esta espécie. Analisa-se cada elemento constitutivo do objeto em relação com o todo.

$1 \quad$ Advogado. Inscrito na $70^{\text {a }}$ Subsecção da OABSP. Graduado pela Faculdade de Direito da Universidade de Franca - UNIFRAN. Texto redigido em dezembro-2008. 
Faz-se um corte epistemológico para tratar da expromissão enquanto implicante na extinção da fiança, ou seja, na liberação do fiador quando não consentir com novo contrato ou adição deste, a figurar este efeito como apodose - conseqüente - na relação da unidade deôntica² ${ }^{2}$.

A fiança é garantia utilizada em larga escala, portanto, de maior receptividade e conhecimento social, e, no entanto, há o desconhecimento alarmante da população sobre os efeitos jurídicos deste contrato acessório de locação. A expromissão é antecedente para extinção desse acessório, nota-se que o Código Civil, art. 838, I, preocupa-se com o consentimento do garantidor para a continuidade dessa prestação, e o mesmo Codex diz que pode ser expressa ou tácita o ato do credor em novar.

A metodologia empregada é a análise das variantes (dependentes) componentes da novação por expromissão - elementos. Análise dos requisitos (validade); fatos específicos; pressupostos básicos. A fonte de pesquisa será a doutrina e jurisprudência. Desta forma, é informativo e ao mesmo tempo analítico, considerando-se o conhecimento científico real (factual). Com prevalência do método indutivo científico, v. g., conforme análise dos arestos colimados.

\section{HISTÓRICO E CONCEITO}

No direito romano, novatio era a substituição do direito de crédito por outro. Desde que o conteúdo do crédito se transferisse ao outro. Era exigido que a dívida anterior se extinguisse por efeito ipso iure, e a outra, a nova, exsurgisse. "Com a obrigação antiga, extinguia-se o que era direito preferencial ou anexo. Somente expressamente se podia estabelecer que se ligasse ao novo crédito" (MIRANDA, 2003, p. 97 , v. 25$)$.

Os juristas modernos tentaram conservar a transfusio ou translatio, pois viram na novação a persistência da matéria jurídica da antiga, ou transfusão da causa ou do conteúdo, ou conexão de matéria. Ou seja, a essência da mesma não haveria de ter sido alterada. Deve-se repelir esta idéia.

No direito moderno, desaparecem as razões para se recorrer à novação sempre que se quisesse modificar o crédito. Não há obstáculo a que se altere sem se conservar a identidade da relação jurídica. Já se pode modificar a prestação devida, quanto ao seu conteúdo, lugar, tempo, condições e termo, ou transmitir o crédito a novo credor (cessão de crédito) ou outra pessoa assumir a dívida, sem se precisar da categoria jurídica da novação. Se se quer

2 Cf.: Carvalho (2008a, p. 24; 2008b, p. 70) sobre a estrutura da norma jurídica, Direito e Lógica, respectivamente; Coelho (2000, p. 57), sobre conectivo deôntico; Borges (2003, p. 55), sobre os valores e as normas na configuração do sistema. 
mais, quebrando-se a identidade do crédito, até aí se pode ir, e a isso provêem os arts. 360 e 362-267 do Código Civil (MIRANDA, 2003, p. 98, v. 25).

A palavra novação origina-se da expressão latina novatio (novus, novo, nova obligatio). Os romanos a definiam como a "a transferência (translatio, transfusio) duma dívida antiga para uma obrigação nova”. (GAGLIANO; PAMPLONA FILHO, 2002, p. 197, v. 2). Novation é "the substitution of a new debtor, creditor, contract, etc., in place of an old one" (OXFORD, 1969, p. 1341, v. 2).

Dá-se a novação quando, por meio de uma estipulação negocial, as partes criam uma nova obrigação, destinada a substituir e extinguir a obrigação anterior. Ruggiero diz: "trata-se de um ato de eficácia complexa, que repousa sobre uma vontade destinada a extinguir um crédito pela criação de um novo" (apud GAGLIANO; PAMPLONA FILHO, 2002, p. 198, v. 2).

Na novação ocorre a constituição da nova dívida com a extinção da primeira. Uma extingue para outra se constituir. Há simultaneidade na constituição de nova dívida e extinção da primeira.

Novar, em linguagem corrente, portanto, é criar uma obrigação nova para substituir e extinguir a anterior. Somente com a criação da obrigação nova é que se pode substituir e, ao mesmo tempo, extinguir a anterior. Não se pode falar em substituição do devedor e existência da obrigação se este se comprometeu a solver obrigação do antigo devedor, que haja o substituído.

Apenas um único ato jurídico, se cria e se extingue. Pode-se, por isso, novar por estipulação contratual, por negócio jurídico unilateral, abstrato, sob a condição de se admitir a extinção em dois momentos: previamente ou depois, pelo credor, nas lições de Miranda (2003, p. 99-100, v. 25) e "se alguém nova dívida é porque extinguiu, com isso, a dívida que existia. Se não houvesse operado novação estaria o devedor duplamente vinculado, - pela primeira e pela outra dívida", e continua:

Daí o sentido estrito e preciso de novar, que não é o de assumir outra dívida, a que se chamaria nova, e sim a de assumir uma em lugar da outra, que se extingue. Com a novação libera-se o devedor e satisfaz-se o credor; mas ambos continuam, um como devedor e outro como credor, noutra relação jurídica, que é outra e posterior, com a particularidade de se ter constituído para a extinção da primeira. Presta-se, em verdade, aliud pro alio.

“Convencionada, portanto, a formação de uma outra obrigação, a primitiva relação jurídica será considerada extinta, sendo substituída pela nova. Aí, então, teremos o fenômeno novatório" (GAGLIANO; PAMPLONA FILHO, 2002, p. 198, v. 2). 
Decorre que a natureza jurídica da novação é negocial, inexistindo por determinação legal ou novação legal, em regra. "A novação é, geralmente, fruto de um acordo ou transação. Freqüentemente é fruto da pressão psíquica que o credor exerce sobre o devedor" (VENOSA, 2006, p. 265, v. 2).

\section{REQUISITOS}

Para se validar a novação, é necessário que haja: a) a existência de uma obrigação anterior; $b$ ) a criação de uma nova obrigação, substancialmente diversa da primeira; c) o animus novandi (requisito subjetivo: REsp 167.709-MG).

Na lição de Gagliano e Pamplona Filho (2002, p. 199, v. 2), sobre a criação de nova obrigação, substancialmente diversa da primeira, diz:

[...] este é um requisito que deve ser estudado com atenção. Ora, consoante já dissemos, a novação consiste na convenção pactuada entre os sujeitos da relação obrigacional, no sentido de criarem uma nova obrigação, destinada a substituir e extinguir a anterior. Dessa forma, a criação de uma "obrigação nova" é requisito indispensável para a caracterização da novação. Mas apenas isso não basta. É preciso, pois, que haja diversidade substancial entre a obrigação antiga e a nova. [...] simples modificações setoriais de um contrato não traduzem novação.

Como a natureza jurídica da novação é de negócio jurídico, para ser válida, exige-se a observância dos pressupostos legais de validade do negócio jurídico, especialmente a capacidade das partes e a legitimação (GAGLIANO; PAMPLONA FILHO, 2002, p. 202, v. 2).

\section{ESPÉCIES}

Modalidade mais comum e de fácil compreensão, ocorre quando as partes de uma relação obrigacional convencionam a criação de uma nova obrigação, para substituir e extinguir a anterior. Art. 360, I, CC - art. 999, I, CC/16. É a substituição objetiva.

A substituição subjetiva pode ser: ativa, passiva ou mista. Dá-se em três hipóteses: $a$ ) por mudança do devedor - novação subjetiva passiva; $b$ ) por mudança do credor - novação subjetiva ativa; e, c) por mudança de credor e devedor - novação subjetiva mista. “[...] Não há necessariamente, modificação do objeto da obrigação, mas apenas de sujeitos, considerando-se, entretanto, quitada a obrigação pactuada com o primeiro devedor" (GAGLIANO; PAMPLONA FILHO, 2002, p. 204, v. 2). 
A novação subjetiva passiva poderá ocorrer de dois modos: por expromissão e por delegação. Objeto deste trabalho é a discussão sobre aquela espécie.

\subsection{NOVAÇÃO POR EXPROMISSÃO}

$\mathrm{Na}$ novação por expromissão, a substituição do devedor se dá independentemente do seu consentimento, por simples ato de vontade do credor, afastando-o, e o substituindo por novo devedor, conforme diz o art. 362 do Código Civil. Se o credor concordar, por ato de expromissão, substitui os sujeitos passivos da relação obrigacional.

A obrigação contraída pelo segundo devedor será considerada nova e aquela que foi substituída, deverá ser tida como adimplida, que exclui da relação obrigacional o devedor daquela que foi substituída, mesmo sem o seu consentimento (GAGLIANO; PAMPLONA FILHO, 2002, p. 205, v. 2), conforme dicção legal, poder ser expressa ou mesmo tácita.

No dizer de Venosa (2006, p. 265, v. 2):

[...] É uma forma que se pode dizer de expulsão do devedor originário. É essa mesma a noção da origem latina do vocábulo. Um terceiro assume a dívida do devedor originário, com o que concorda o credor. Não há necessidade de concordância do primeiro devedor: "a novação, por substituição do devedor, pode ser efetuada independente de consentimento deste" (art. 362; antigo, art. 1.001). A situação vem, evidentemente, em benefício do credor, que aceitará um devedor em melhores condições de adimplir. As relações entre o primitivo devedor e o novo são irrelevantes para o credor e para o instituto da novação. [...] Deve existir, em síntese, a intenção de novar. O novo devedor, um amigo do primitivo, chega até o credor e diz que deseja, desde aquela oportunidade, ser o responsável pelo débito; o credor dá quitação ao devedor primitivo e contrai nova obrigação ao amigo que se apresentou.

Expromission é "the act by which a new debtor undertakes the debt or a former one, who is thereby released" (OXFORD, 1969, p. 659, v. 1), ou seja, é o ato pelo qual um novo devedor se compromete a uma dívida ou a de um antigo, que é assim liberado.

\section{EFICÁCIA DA NOVAÇÃO E O INCISO I DO ART. 838 DO CÓDIGO CIVIL}

O inciso I do art. 838 do Código Civil (antigo art. 1.503 do CC/16) é modalidade de extinção da fiança. Ainda que solidário, o fiador ficará desobrigado se, sem o seu consentimento, o credor conceder moratória ao devedor, conforme a dicção legal. A 
análise comporta observar o limite da responsabilidade solidária entre locatário e fiador, e o fator tempo para a fiança.

Ficará desobrigado em três casos, mas ainda ligado ao devedor, ou seja, aqui somente importará o inciso I. Se, sem consentimento seu, o credor conceder moratória ao devedor. "[...] A moratória é a prorrogação do prazo de uma dívida além do prazo em que já se tenha tornado exigível”, diz Santos (1977, p. 491, v. 29). E, explica:

A moratória constitui novação e a fiança para uma dívida não se entende dada para novação. É manifesto que o devedor, pedindo tal prorrogação, diz Cunha Gonçalves, confessa implicitamente que não está habilitado a pagar; e sendo certo que, durante o novo prazo, pode sobrevir a insolvência do mesmo devedor, é justo que o fiador não fique sujeito a este arbítrio do credor.

A fiança é dada com limitação de tempo, e se extingue ao fim do prazo determinado, ou quando por tempo indeterminado, como a hipótese do antigo art. 1.500 do Código Civil de 1916. E a obrigação determinada pela redação do novo art. 835 do Código Civil, mesmo por prazo indeterminado, ficará o fiador obrigado 60 dias após a notificação do credor.

Santos (1977, p. 483, v. 27) diz que o fiador não poderia, contra a sua vontade, ficar indefinidamente sujeito à responsabilidade da fiança, pois não admite interpretação diversa. E, Alves (2002, p. 754) diz:

\begin{abstract}
Nesse ponto, o novo Código Civil traz mudanças significativas, que merecem ser ressaltadas: a um, porque admite a exoneração por simples comunicação (notificação) ao credor, independentemente de anuência deste ou do devedor principal, ou mesmo de sentença judicial; a dois, porquanto, pelo prazo de sessenta dias, contados da notificação ao credor, o fiador continuará vinculado por todas as obrigações assumidas pelo devedor, produzindo, daí, efeitos ex nunc, voltados apenas para o futuro.
\end{abstract}

Diniz (2006, p. 177), sobre as garantias locatícias, são elas acessórias, acompanham o principal, vencendo-se com ele, no prazo marcado para pagamento do débito garantido, vigendo até que haja devolução do imóvel alugado pelo locatário, ou conforme disposição contratual em contrário, quando se opera o vencimento antecipado das garantias antes da restituição do imóvel locado. Santos (2002, p. 253) diz que os fiadores não são responsáveis por aumentos de locativos previstos em novos contratos ou aditamentos contratuais dos quais não participaram.

Pacheco (2000, p. 319-320) diz: "O fiador fica exonerado, desde que foi alterado o objeto da locação sem a participação dos fiadores e efetuado acordo, quanto ao pagamento do débito, entre locador e locatário, em ação de despejo", e, "se houver dois 
fiadores, a concessão de moratória ao afiançado, com a anuência de apenas um deles, desobriga o outro co-fiador (STJ, DJU de 26.10.1992)”.

"A novação extingue o crédito ipso iure. Termina, portanto, a mora. Os privilégios, os direitos reais de garantia e a fiança, ligados a ele, extinguem-se" (MIRANDA, 2003, p. 141, v. 25). A eficácia da novação tem como efeito, a extinção da fiança. Deste modo, liberado o garantidor se não contraiu obrigação nova ou dela não participou, está liberado da obrigação. Monteiro (1967, p. 385, v. 2) diz que importa exoneração do fiador novação feita sem seu consenso com o principal devedor.

Nery Júnior e Nery (2006, p. 574), sobre acordo judicial sem a anuência dos fiadores, colimam aresto do $2^{\mathrm{a}}$ TACivSP, $10^{\mathrm{a}}$ Câm., Ap 617188-0/2, rel. Juiz Soares Levada, v. u., j. 12.12.2001, e ventilam:

Se locador e locatária firmaram acordo judicial em ação de despejo, que estabeleceu novas condições para a dívida inicial, sem a anuência dos fiadores, configurou-se moratória que os desobrigou da garantia, conforme o CC/1916 1503 I [CC 838 I]. É irrelevante o fato de eles terem sido cientificados da ação, uma vez que a mera cientificação não os tornou parte na demanda.

No aresto do TJSP da $34^{\mathrm{a}}$ Câm. Dir. Priv., Agravo de Instrumento n. 11852030/0, rel. Rosa Maria de Andrade Nery, v. u., j. 06.08.2001, diz que se o título que embasa a execução é fundado em acordo entre as partes, sem anuência dos fiadores, a transação judicial desobriga os fiadores.

\section{CONCLUSÃO}

A importância da pactuação de obrigação entre locador e locatário sem a anuência do fiador, libera-o de adimplir essa obrigação, seja porque não pactuou, seja porque não consentiu com sua anuência na moratória concedida ao devedor pelo credor.

Esta é a dicção legal do inciso I do art. 838 do Código Civil, e a expromissão, espécie do gênero novação, por substituição passiva. Nesta espécie, a substituição do devedor ocorre independentemente da sua vontade, no caso, a substituição da obrigação por uma nova (constituição), gera a novação que, se não há menção ao fiador, logo ele não se solidariza com o devedor (locatário) na nova obrigação.

$\mathrm{O}$ ato de expromissão substitui os sujeitos passivo da relação obrigacional originária e afasta quem dela não participou, seja em relação a devedores co-obrigados, seja a de co-fiadores; se há participação, quem anuiu, consentiu, está obrigado pela nova 
relação obrigacional; se, quem não anuiu, não consentiu, não está obrigado pela nova relação obrigacional.

Também, quando há estipulação contratual para determinado tempo para a garantia fideijussória, condicionada pela entrega das chaves, estender-se-á até a efetiva entrega do prédio. Ou caso em que se opera o dies a quo e há prorrogação tácita, deverá o fiador notificar o credor da sua liberação e, portanto, rompimento do liame garantidor; e se há não prorrogação tácita, mas acordo para pagamento (transação, moratória) entre locatário e locador, sem observância do consentimento do fiador, libera-o, pois novação tácita.

\section{REFERÊNCIAS}

ALVES, J. F.; FIUZA, R. (Coord.). Novo código civil comentado. São Paulo: Saraiva, 2002.

BORGES, A. W. Preâmbulo da Constituição \& a ordem econômica. Curitiba: Juruá, 2003.

BRASIL. Superior Tribunal de Justiça. Processual Civil. Direito Civil. REsp n. 167709MG. $5^{\text {a }}$ Turma. Relator Min. Edson Vidigal. J. 20.10.1998. Disponível em: $<$ http://www.stj.jus.br>. Acesso em: 14 set. 2008.

CARVALHO, P. B. Direito tributário: fundamentos jurídicos da incidência. 6 ed. São Paulo: Saraiva, 2008a.

Direito tributário, linguagem e método. 2 ed. São Paulo: Noeses, 2008b.

COELHO, F. U. Roteiro de lógica jurídica. 3 ed. Guarulhos: Max Limonad, 2000.

DINIZ, M. H. Lei de locações de imóveis urbanos comentada: (Lei n. 8.245, de 1810-1991). 8 ed. São Paulo: Saraiva, 2006.

GAGLIANO, P. S.; PAMPLONA FILHO, R. Novo curso de direito civil: obrigações. São Paulo: Saraiva, 2002. v. 2.

MIRANDA, M. P. de. Tratado de direito privado. Campinas: Bookseller, 2003. v. 25.

MONTEIRO, W. de B. Curso de direito civil. Direito das obrigações. 5 ed. São Paulo: Saraiva, 1967. v. 2.

NERY JÚNIOR, N.; NERY, R. M. de A. Código civil comentado. 4 ed. São Paulo: Revista dos Tribunais, 2006.

PACHECO, J. da S. Tratado das locações, ações de despejo e outras. São Paulo: Revista dos Tribunais, 2000. p. 319. 
PAMPLONA FILHO, R.; GAGLIANO, P. S. Novo curso de direito civil: obrigações. São Paulo: Saraiva, 2002. v. 2.

SANTOS, G. dos. Locação e despejo: comentários à Lei 8.245/91. 5 ed. São Paulo: Revista dos Tribunais, 2002.

SANTOS, J. M. de C. Código civil brasileiro interpretado, principalmente do ponto de vista prático. Direito das obrigações (arts. 1.363-1.504). 9 ed. Rio de Janeiro: Freitas Bastos, 1977. v. 29.

SÃO PAULO. Tribunal de Justiça de São Paulo. Agravo Instrumento n. 1185203-0/0. $34^{\mathrm{a}}$ C.Priv. Relator Des. Rosa Maria de Andrade Nery. J. 06.08.2001. Disponível em: <http://www.tj.sp.gov.br>. Acesso em: 14 set. 2008.

SÃO PAULO. Tribunal de Justiça de São Paulo. Ap. Cível n. 617188-0/2. 10 a TA.Civ. Relator Des. Soares Levada. J. 12.12.2001. Disponível em: 〈http://www.tj.sp.gov.br>. Acesso em: 14 set. 2008.

OXFORD UNIVERSITY PRESS. The Oxford universal dictionary illustrated: an illustrated edition of the shorter oxford English dictionary. 3 ed. Great Britain: Onions, 1969. v. 1 e 2.

VENOSA, S. de S. Direito civil: teoria geral das obrigações e teoria geral dos contratos. 6 ed. São Paulo: Atlas, 2006. v. 2. 
